\title{
ACTIVATED POLYPROPYLENE MEMBRANES WITH ION-EXCHANGE POLYMERS TO TRANSPORT CHROMIUM IONS IN WATER
}

\author{
YESID TAPIERO ${ }^{1}$, BERNABÉ L. RIVAS ${ }^{1 *}$ AND JULIO SÁNCHEZ ${ }^{2}$

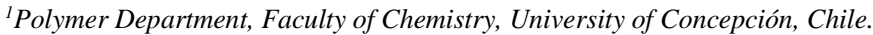 \\ ${ }^{2}$ Departamento de Ciencias del Ambiente, Facultad de Química y Biología, Universidad de Santiago de Chile, USACH, Casilla 40, Correo 33, Santiago, Chile.
}

\begin{abstract}
Polypropylene (PP) membranes were modified by in situ radical-polymerizations of functional monomers forming networks inside the pores. The main experimental conditions studied include the functional monomer concentration and crosslinking concentration.

The modified membranes were characterized by scanning electron microscopy, charge density properties, and Donnan dialysis for chromium ion transport. The experimental data of the transport of $\mathrm{Cr}(\mathrm{III})$ and $\mathrm{Cr}(\mathrm{VI})$ ions were fitted to mathematical models (a polynomial fit as the first step and then the change in the concentration rates of both phases). The 4-order polynomial equation for the $\mathrm{Cr}(\mathrm{III})$ ions and the 7-order polynomial equation for the $\mathrm{Cr}(\mathrm{VI})$ ions provide better fits to the data and aid in predicting the chromium concentration values for any time.
\end{abstract}

Keywords: Polypropylene, ion exchange membrane, chromium ion transport, Donnan dialysis, interpenetrating polymer networks (IPNs).

\section{INTRODUCTION}

Chromium ions are valued in the manufacturing processes of surface plating and chromium electroplating (decorative and hard plating), stainless-steel handwork, and other alloys, as well as the manufacturing of inks, concrete, bricks, photographs, paints, and plastics [1,2]. However, they can generate water pollution due to their high toxicity. The World Health Organization requires a maximum concentration limit of $0.05 \mathrm{mg} / \mathrm{L} \mathrm{Cr}$ (III) or $\mathrm{Cr}$ (VI) [3].

Chromium ions are stable and abundant under oxidation states as trivalent (Cr(III)) and hexavalent (Cr(VI)) chromium. The $\mathrm{Cr}$ (III) ion is essential for life at a low concentration [4]. The $\mathrm{Cr}(\mathrm{III})$ ion depends on the $\mathrm{pH}$ value and the concentration, and it can be soluble or precipitate. At acidic $\mathrm{pH}$ values below 3.6, the main $\mathrm{Cr}(\mathrm{III})$ species that dissolve in water $\operatorname{are~} \mathrm{Cr}(\mathrm{OH})_{2}{ }^{+}, \mathrm{Cr}(\mathrm{OH})_{3}{ }^{0}$, and $\mathrm{Cr}(\mathrm{OH})_{4}{ }^{-}$chromyl ions. $\mathrm{Cr}(\mathrm{III})$ precipitates as $\mathrm{Cr}(\mathrm{OH})_{3} \times \mathrm{nH}_{2} \mathrm{O}$, when the $\mathrm{pH}$ values are higher [4].

On the other hand, $\mathrm{Cr}(\mathrm{VI})$ can be dissolved in water, and the $\mathrm{pH}$ range and concentration are not important. It is important to know the speciation of $\mathrm{Cr}(\mathrm{VI})$, for example, at basic $\mathrm{pH}$ values, it exists as chromate $\left(\mathrm{CrO}_{4}{ }^{2-}\right)$ ions, and at acidic $\mathrm{pH}$ values, it exists as acid chromate $\left(\mathrm{HCrO}_{4}^{-}\right)$or dichromate $\left(\mathrm{Cr}_{2} \mathrm{O}_{7}{ }^{2-}\right)$ ions or a mixture of the two, depending on the concentration [5].

Currently, an increasing scientific area involves techniques to remove and recover $\mathrm{Cr}(\mathrm{III})$ and $\mathrm{Cr}(\mathrm{VI})$ using mainly membrane technologies such as a concentration gradient (Donnan dialysis, diffusion dialysis and dialysis [6, 7]), a pressure gradient (ultrafiltration, nanofiltration, and reverse osmosis $[8,9]$ ), an electromotive force gradient (electrodialysis [10]), selective transport (liquid, emulsified, and supported membranes [11, 12])), ion-exchange [13], precipitation [14] and adsorption [15] methods. However, the problem in using membrane technology appears when ions are of the same charge and are similar in nature or size.

Donnan dialysis is an attractive technique because it is not an expensive or complicated process, and it also uses the difference $\mathrm{n}$ electrochemical potential on two sides of a membrane as the driving force [16]. The process reacts to the desired selection of a functional work membrane. The applications of Donnan dialysis have expanded to many areas, such as nitrate removal from natural water [17], gold(III) separation from electronic waste solutions using a pore-filled anion exchange membrane [18], copper removal [19], and $\mathrm{Cr}(\mathrm{VI})$ ion removal using commercial anion-exchange membranes [20].

The performance of the Donnan dialysis process is based on the selection of the ion exchange membrane. The ion exchange membrane needs to show a stable microstructure and a complete distribution of functional groups.

The modification of macroporous polymeric membranes for the preparation of interpenetrating polymer networks (IPNs) is an attractive alternative. IPNs architectures are developed on the molecular scale when two or more polymer networks are partially and non-covalently crosslinked and cannot be separated by link breakages via chemical or physical methods [21].
Pore-filled membranes with an ion exchange resin are IPNs materials because the macro- or microporous host support membrane provides chemical, mechanical, and thermal stability to protect the active ion-exchange polymer resin. The most common commercial porous membranes, which can be considered as supports, are made of polypropylene (PP) or polyethylene [22]. The most characteristic properties of these polyolefin materials are good thermal, mechanical, and chemical stability [23].

On the other hand, ion-exchange polymer networks have been used for the removal of $\mathrm{Cr}(\mathrm{VI})$. Such IPNs are effective ion exchangers used in the removal processes of chromate ions [24]. Alternatively, an IPNs based on poly(glycidyl methacrylate- $N$-methyl-D-glucamine) (P(GMA-NMG)) has shown efficient chelating properties for the retention of chromium ions [25, 26], whereas in the case or $\mathrm{Cr}(\mathrm{III})$ removal, the most characteristic ion exchange polymer networks were composed of poly(sodium(styrenesulfonate)) ( $\mathrm{P}(\mathrm{SSNa}))$ and poly(acrylic acid) (P(AA)) [27, 28].

In this research, the main goal is to activate a commercial macroporous PP membrane with ion-exchange IPNs, characterize them and then analyze their transport properties with respect to $\mathrm{Cr}(\mathrm{III})$ and $\mathrm{Cr}(\mathrm{VI})$ ion transport via the Donnan dialysis technique, fitting this experimental data to a mathematical model.

\section{EXPERIMENTAL METHODS}

\section{Materials}

Commercial macroporous isotactic PP membranes were employed as the support (0.6- $\mu \mathrm{m}$ pore size, AN06 Merck Millipore). Ammonium persulfate, APS, (Merck), $N, N^{\prime}$-methylene-bis-acrylamide, MBA, (Aldrich), glycidyl methacrylate, GMA, (Aldrich), $N$-methyl-D-glucamine, NMG, (Aldrich), acrylic acid, AA, (Aldrich), (ar-vinylbenzyl)trimethylammonium chloride, CIVBTA, (Aldrich), sodium styrenesulfonate, SSNa (Aldrich), 15-kDa polyvinyl alcohol, PVA (Merck), 15-kDa poly(ethyleneimine), PEI, (Aldrich), ethanol (Merck), and type I deionized water (Thermo Fisher TKA scientific) were employed for the IPNs synthesis.

$\mathrm{HNO}_{3}$ (Merck) and $\mathrm{NaOH}$ (Merck) were used to control the pH. $\mathrm{K}_{2} \mathrm{Cr}_{2} \mathrm{O}_{7}$ (Merck) and $\mathrm{Cr}\left(\mathrm{NO}_{3}\right)_{3} \times 9 \mathrm{H}_{2} \mathrm{O}$ (Merck) were the chromium sources. $\mathrm{NaCl}$ (Merck) was the extraction reagent.

An aluminum flat reactor and Memert Equilab oven were used for the radical polymerization of the functional IPNs.

\section{Synthesis of the ion exchange IPNs}

The commercial macroporous membranes were prepared washing them with an aqueous mixture of $50 \% \mathrm{w} / \mathrm{w}$ ethanol. This wash helped to eliminate all waste and to wet the pores. As a first step, it was necessary that the surface and porewalls of the PP membranes were hydrophilized. Then, pressure injection was used for impregnation of the reactive solution into the membrane before polymerization. 
A stirred-cell filtration unit (Millipore, model 8050) was used to inject the pressurized reactive monomer solution into the commercial macroporous PP membrane.

The hydrophilization process for the commercial PP membranes were made following the method described in literature [27], and the 15-kDa polyvinyl alcohol and 15-kDa poly(ethyleneimine) were used as hydrophilic polyelectrolytes and grafted on the wall pores. The glycidyl methacrylate- $N$ methyl-D-glucamine (GMA-NMG) monomer was prepared following the method previously described [29, 30].

The macroporous PP membrane was placed inside of a stirred-cell filtration unit, and $20 \mathrm{~mL}$ of the aqueous mixture solution of the functional reactive monomer, MBA crosslinking reagent and APS radical initiator agent was passed through the membrane using nitrogen gas and a pressure of 1 bar. Only one injection was performed. The in situ free-radical polymerization was performed inside the membrane pores and on the surface at $70{ }^{\circ} \mathrm{C}$ for $24 \mathrm{~h}$. Figure 1 shows the scheme of the experimental design for the ion exchange IPNs formation.

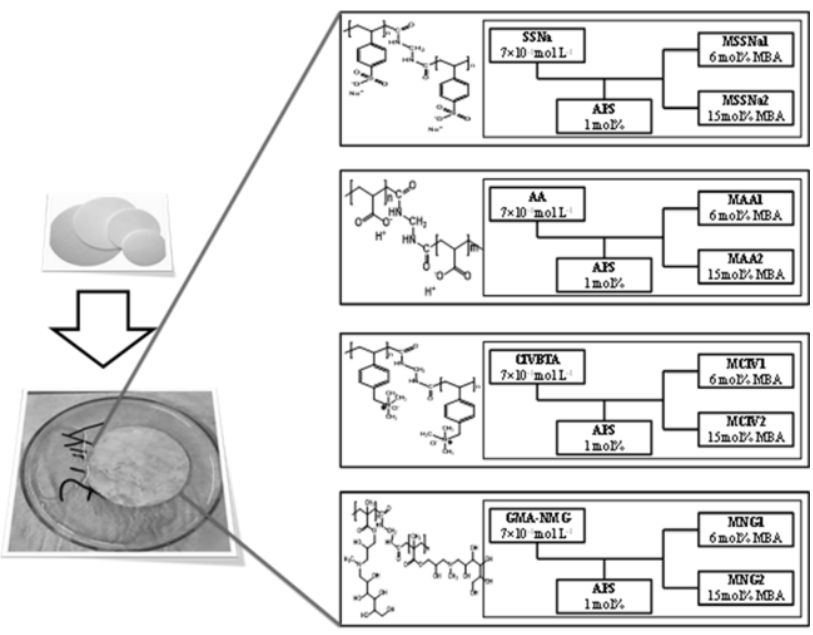

Figure 1. Experimental design for the preparation of the IPNs.

\section{Characterization}

Volumetric flux. In this test, the water pass capacity through the modified membranes was analyzed in comparison with that of PP (MPP). The stirred-cell filtration unit (Amicon) was used as the pressure equipment works with nitrogen gas. The filtration time for $50 \mathrm{~mL}$ of deionized water was measured.

Modification degree. The modification $\left(\% \Delta \mathrm{G}_{\mathrm{m}}\right)$ was gravimetrically measured. First, the MPP were weighed. These membrane samples (dried samples) were again weighed after the modification process, and $\% \Delta \mathrm{G}_{\mathrm{m}}$ was determined from equation 1 :

$$
\% \Delta G_{m}=\frac{\left(w_{f}-w_{0}\right)}{w_{0}} * 100 \%
$$

Where $w_{f}$ is the dry IPN membrane weight $(\mathrm{g})$, and $w_{0}$ is the unmodified membrane weight $(\mathrm{g})$.

Water uptake capacity. The weight of the dried IPNs-modified membrane was measured before swelling with distilled deionized water for $24 \mathrm{~h}$ at room temperature. The water excess was removed from the modified membrane, and the weight was measured 3 times. The water uptake percent $\left(\% \Delta \mathrm{W}_{\mathrm{w}}\right)$ was calculated with equation 2 :

$$
\% \Delta W_{w}=\frac{\left(W_{w e t}-W_{d r y}\right)}{W_{d r y}} * 100 \%
$$

Where $W_{\text {wet }}$ is the wet IPNs membrane weight $(\mathrm{g})$, and $W_{d r y}$ is the dry IPN membrane weight $(\mathrm{g})$.

Scanning electron microscopy (SEM). This microscopy was used to analyze the morphology changes between the modified and unmodified membranes. A $20000 \mathrm{kV}$ JOEL microscope (JSH 6380LV model) was used.
Charge density properties. Brookhaven Zeta Plus equipment was used. The samples were cut into thin pieces and submerged in $0.05 \mathrm{M} \mathrm{KCl}$ at $\mathrm{pH} 3.0,5.0$, 7.0, and 9.0. The $\mathrm{pH}$ was controlled using $\mathrm{HCl}$ and $\mathrm{NaOH}$. The electrokinetic potential (C) was determined from the ionic mobility $\left(\mu_{\mathrm{e}}\right)$ using the Smoluchowski equation (equation 3):

$$
\mu_{e}=(\varepsilon * \varsigma) / \eta
$$

The charge density $\left(\sigma^{*}\right)$ was calculated from the electrokinetic potential $(\mathcal{\varsigma})$ using equation 4 :

$$
\sigma^{*}=\left[\left(7.331 \times 10^{-3} C\right)^{1 / 2} \sinh (\varsigma / 51.39)\right] * \frac{1.0 \AA^{2}}{\left(1.0 \times 10^{-10}\right)^{2}}
$$

Where $\mu_{\mathrm{e}}$ is the ionic electrophoretic mobility $\left(\mu \mathrm{s}^{-1} \mathrm{~V}^{-1} \mathrm{~cm}\right), \varepsilon$ is the liquid permittivity $\left[\mathrm{J} \mathrm{V}^{-1} \mathrm{~m}^{-1}\right], \mathrm{C}$ is the $\mathrm{KCl}$ concentration, $\eta$ is the liquid viscosity, $\sigma^{*}$ is the charge density, and $\zeta$ is electrokinetic potential or zeta potential [mV] [31].

Donnan dialysis: A two-chamber diffusion cell (feed and extraction phases) was separated by an IPN membrane (see Figure 2). Each chamber had a $100 \mathrm{~mL}$ capacity and was filled with $50 \mathrm{~mL}$ of the work solution for the tests.

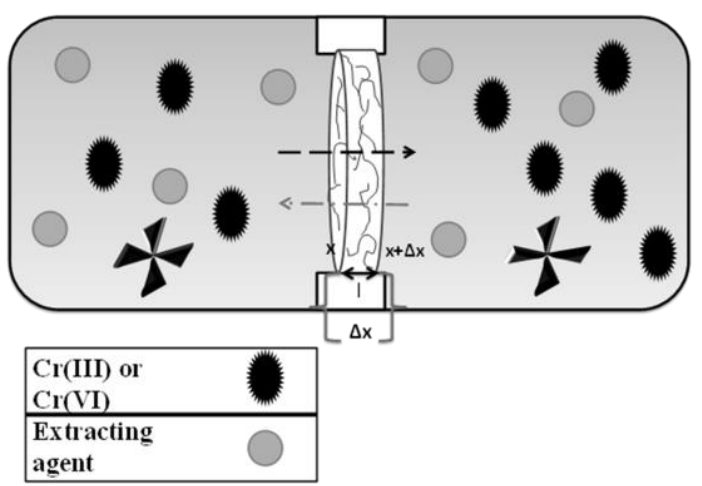

Figure 2. Scheme representative of the Donnan dialysis process.

The feed chamber contains the $\mathrm{Cr}(\mathrm{III})$ at acid $\mathrm{pH}$. For $\mathrm{Cr}$ (III) ions, two experiments were performed depending of the concentration $\left(8.0 \times 10^{-3} \mathrm{~mol} \mathrm{~L}^{-1}\right.$ and $\left.6.4 \times 10^{-3} \mathrm{~mol} \mathrm{~L}^{-1}\right)$. The $\mathrm{pH}$ value was maintained at 3.0. The modified membranes with $\mathrm{P}(\mathrm{SSNa})$ and $\mathrm{P}(\mathrm{AA})$ networks were used for $\mathrm{Cr}$ (III) transport. The extraction chamber was filled with a mixture of $1.0 \mathrm{~mol} \mathrm{~L}-1 \mathrm{NaCl}$ and $1 \times 10$ ${ }^{2} \mathrm{~mol} \mathrm{~L}^{-1} \mathrm{HNO}_{3}$. Samples were taken from both the feed chamber and extraction chamber to measure the $\mathrm{Cr}$ (III) ion concentration. A $3 \mathrm{~mL}$ sample was measured every $60 \mathrm{~min}$ for 6 and $8 \mathrm{~h}$. The samples were returned to the extraction chamber after measuring the $\mathrm{Cr}(\mathrm{III})$ ion concentration.

In addition, for $\mathrm{Cr}(\mathrm{VI})$ ions, the feed chamber was filled with the $\mathrm{Cr}(\mathrm{VI})$ solution. The modified membranes with $\mathrm{P}(\mathrm{ClVBTA})$ and $\mathrm{P}(\mathrm{GMA}-\mathrm{NMG})$ networks were used for $\mathrm{Cr}(\mathrm{VI})$ ion transport. In the feed chamber, the $\mathrm{pH}$ value was changed to between 3.0 and 9.0; the same $\mathrm{pH}$ adjustment was made in the extraction chamber and the extraction agent was the $1 \mathrm{~mol} \mathrm{~L}^{-1} \mathrm{NaCl}$ solution. The $\mathrm{Cr}(\mathrm{VI})$ ion concentration varied between $1.0 \times 10^{-4} \mathrm{~mol} \mathrm{~L}^{-1}$ and $5.0 \times 10^{-4} \mathrm{~mol} \mathrm{~L}^{-1}$. Every $60 \mathrm{~min}$ for 6 to $8 \mathrm{~h}, 3 \mathrm{~mL}$ was extracted from the extraction chamber. The samples were returned to the extraction chamber after measuring the $\mathrm{Cr}(\mathrm{VI})$ ion concentration.

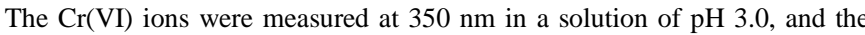
$\mathrm{Cr}$ (III) ion concentration was measured at a wavelength of $573 \mathrm{~nm}$ for acidic $\mathrm{pH}$ [29]. A Cary 100 Scan UV-visible spectrophotometer from Varian was used to directly measure the $\mathrm{Cr}(\mathrm{VI})$ and $\mathrm{Cr}(\mathrm{III})$ ion concentrations. Origin ${ }^{\circledR}$ Pro 8 software was used to make the profile graphics. A UB-10 $\mathrm{pH} / \mathrm{mV}$ meter from Denver instrument was used to measure the $\mathrm{pH}$ solution.

\section{Theoretical background of mathematical model}

To find the target solute concentration profile and the flux across the ion exchange IPNs membranes, a mass balance on a thickness of $\Delta \mathrm{x}$ was performed (see Figure 2). The ion exchange IPNs membranes have properties common to those of heterogeneous membranes and homogeneous membranes. Therefore, these membranes are modeled as assumed homogeneous materials. 
The membrane phase requires the following assumptions: the charge density is uniformly distributed throughout the structure; the mass transfer process is in a pseudo steady state and occurs in only one direction; the control of separation obeys to the Donnan equilibrium; the partition coefficients $(\mathrm{H})$ of the counterions have constant values; and the ion exchange reaction on the membrane surface is very fast [16]. The control of volume for the Donnan dialysis process needs the following assumptions: perfectly mixed aqueous solution phases (feed and extraction), constant-density phases, environmental temperature, constant partition coefficients of ions, constant volumes (feed and extraction), and pseudo-steady-state operation [32].

The global mass conservation equation for the Donnan dialysis process is given in equation 5 :

$$
\frac{\partial C}{\partial t}=D_{e f f} * \frac{\partial^{2} C}{\partial x^{2}}
$$

Where $t$ is the time in minutes, $C$ is the concentration of the chromium ions in mol L ${ }^{-1}, x$ is the thickness of the membrane in $\mathrm{m}, D_{\text {eff }}$ is the effective ion diffusion constant in $\mathrm{m}^{2} \mathrm{~s}^{-1}$, and $\frac{d C_{i}}{d x}$ is the concentration gradient with respect to the thickness of the membrane in $\mathrm{mol} \mathrm{L}^{-1} \mathrm{~m}^{-1}$.

The initial boundary conditions for $C(x, t)$ (concentration) are:

$$
\begin{aligned}
& C(x, 0)=0 \\
& C(0, t)=H * C_{1}(t) \\
& C(x+\Delta x, t)=H * C_{2}(t)
\end{aligned}
$$

Assuming that the stirred chambers (feed and extraction) are closed except for the mass transfer to or from the membrane, the following is obtained:

$$
\begin{aligned}
& v * \frac{d C_{\text {Feed }}}{d t}=-a * J_{i}(x, x=0) \\
& v * \frac{d C_{\text {Receiving }}}{d t}=-a * J_{i}(x, x+\Delta x)
\end{aligned}
$$

where $C_{\text {Feed }}$ is the target ion concentration in the feed phase in $\mathrm{mol} \mathrm{L}^{-1}$, $C_{\text {Receiving }}$ ) is the target ion concentration in the receiving phase in $\mathrm{mol} \mathrm{L}^{-1}, a$ is the active area of membrane in $\mathrm{m}^{2}, J_{i}$ is the flux through of the membrane by the anion in $\mathrm{mol} \mathrm{m}^{2} \mathrm{~s}^{-1}$, and $v$ is the mass average velocity or convection velocity on the membrane in $\mathrm{m} \mathrm{s}^{-1}$.

Evaluating the target solute fluxes just inside the membrane, the mass balance is:

$$
\begin{aligned}
& J_{i}(x, x=0)=-D_{e f f} * \frac{\partial C(0, t)}{\partial x} \\
& J_{i}(x, x+\Delta x)=-D_{e f f} * \frac{\partial C(x+\Delta x, t)}{\partial x}
\end{aligned}
$$

The mass transport process inside the modified membrane is controlled by Fick's law. Under the condition of no electrical current, the sum of the flux of feed ions $\left(J_{i}\right)$ and of driving ions $\left(J_{j}\right)$ is zero, as in equation 13:

$$
z_{i} J_{i}+z_{j} J_{j}=0
$$

where $z_{i}$ and $z_{j}$ are the valence electrons of the anion and cation respectively.

Under electroneutrality, the total concentration of all counter ions in the membrane is equal to that of the fixed ions, which is denoted as the ion exchange capacity as indicated in equation 14:

$z_{i} C_{i}+z_{j} C_{j}=Q$

where $C_{i}$ and $C_{j}$ are the anion concentration inside the membrane and the cation concentration inside the membrane in $\mathrm{mol} \mathrm{L}^{-1}$.

In this case, the chromium ( $\mathrm{Cr}(\mathrm{III})$ or $\mathrm{Cr}(\mathrm{VI})$ ) driving ions diffuse through the membrane from the feed chamber to the extraction chamber, and the extraction agent $\left(\mathrm{Na}^{+}\right.$or $\left.\mathrm{Cl}^{-}\right)$in the opposite direction.

The analytical solution to the first Fick law equation (equations 11 and 12) is:

$$
C_{\text {Feed }, i}=\frac{C_{i f}^{0}}{2}\left(1+e^{-\frac{t}{\tau}}\right)
$$

For the feed chamber; and

$$
C_{\text {Receiving }, i}=\frac{C_{i f}^{0}}{2}\left(1-e^{-\frac{t}{\tau}}\right)
$$

For the extraction chamber; where:

$\tau=\frac{v *(x+\Delta x)}{2 * a * D_{e f f} * H}$ where the $C_{i f}^{0}$ is the target ion concentration in the feed phase at time zero in mol L ${ }^{-1}$, and $\tau$ is the constant time in minutes.

On the other hand, it is possible to employ the experimental data of the concentration profile as function of time and the particular membrane properties; for example, the feed and receiving concentration $(\mathrm{Cr}(\mathrm{III})$ and $\mathrm{Cr}(\mathrm{VI})$ ion)-time experimental data are close-fitting to a polynomial equation of order $\mathrm{n}$ :

$$
\begin{aligned}
& C_{\text {Feed }, i}=\beta_{0}+\beta_{1} t+\beta_{2} t^{2}+\beta_{3} t^{3}+\beta_{4} t^{4} \\
& C_{\text {Receiving }, i}=\beta_{0}+\beta_{1} t+\beta_{2} t^{2}+\beta_{3} t^{3}+\beta_{4} t^{4}
\end{aligned}
$$

Equations 18 and 19 are for the $\mathrm{Cr}(\mathrm{III})$ ions.

Additionally,

$$
\begin{aligned}
& C_{\text {Feed }, i}=\beta_{0}+\beta_{1} t+\beta_{2} t^{2}+\beta_{3} t^{3}+\beta_{4} t^{4}+\beta_{5} t^{5}+\beta_{6} t^{6}+\beta_{7} t^{7} \\
& C_{\text {Receiving }, i}=\beta_{0}+\beta_{1} t+\beta_{2} t^{2}+\beta_{3} t^{3}+\beta_{4} t^{4}+\beta_{5} t^{5}+\beta_{6} t^{6}+\beta_{7} t^{7}
\end{aligned}
$$

where $\beta_{i}$ is the coefficient of the concentration of ions at the bulk solution in mol L ${ }^{-1}$. Equations 20 and 21 are related to the $\mathrm{Cr}(\mathrm{VI})$ ions.

Then, the derivative of the concentration equations are taken with respect to time, such as:

$$
\begin{aligned}
& \frac{d C_{F e e d, i}}{d t}=\beta_{1}+\left(2 * \beta_{2}\right) t+\left(3 * \beta_{3}\right) t^{2}+\left(4 * \beta_{4}\right) t^{3} \\
& \frac{d C_{\text {Receiving, } i}}{d t}=\beta_{1}+\left(2 * \beta_{2}\right) t+\left(3 * \beta_{3}\right) t^{2}+\left(4 * \beta_{4}\right) t^{3}
\end{aligned}
$$

For the $\mathrm{Cr}(\mathrm{III})$ ions.

$$
\begin{aligned}
& \frac{d C_{\text {Feed, }, i}}{d t}=\beta_{1}+\left(2 * \beta_{2}\right) t+\left(3 * \beta_{3}\right) t^{2}+\left(4 * \beta_{4}\right) t^{3}+\left(5 * \beta_{5}\right) t^{4}+\left(6 * \beta_{6}\right) t^{5}+\left(7 * \beta_{7}\right) t^{6} \\
& \frac{d C_{\text {Receiving, } i}}{d t}=\beta_{1}+\left(2 * \beta_{2}\right) t+\left(3 * \beta_{3}\right) t^{2}+\left(4 * \beta_{4}\right) t^{3}+\left(5 * \beta_{5}\right) t^{4}+\left(6 * \beta_{6}\right) t^{5}+\left(7 * \beta_{7}\right) t^{6}
\end{aligned}
$$

\section{For the $\mathrm{Cr}(\mathrm{VI})$ ions.}

At any time, the concentration and the concentration change velocity are known. If the $n$ order of the polynomial is low, then the polynomial fitting does not adhere to the tendency of the data. However, if the $n$ order of the polynomial is high, the graphical curve of the polynomial fit achieves crests and valleys for most of the data. In this research, for the $\mathrm{Cr}(\mathrm{III})$ ions, the polynomial fit is $4^{\text {th }}$ order, and for the $\mathrm{Cr}(\mathrm{VI})$ ions, the fit is $7^{\text {th }}$ order.

\section{RESULTS AND DISCUSSION}

\section{Characterization of modified membranes}

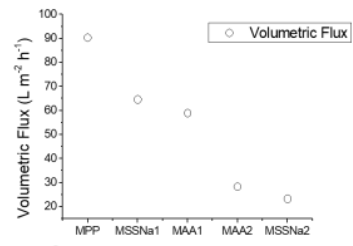

a

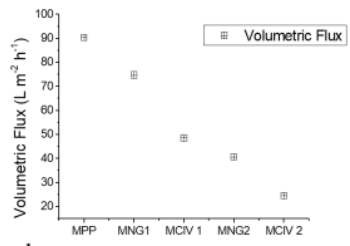

b
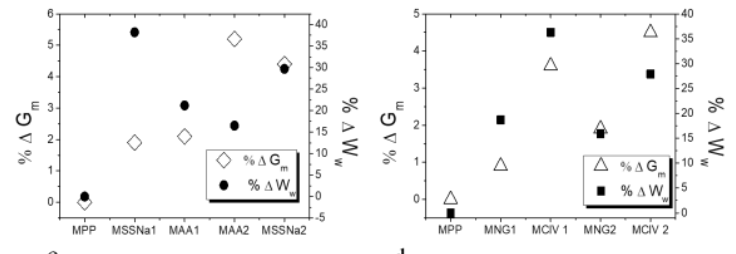

Figure 3. Profile of the fundamental characterization of the modified membranes.

The efficiency of the modified method for functionalizing membranes was tested by comparing the changes in response to the volumetric flux of water, employing an unmodified macroporous-pattern reference membrane.

Figure 3 shows the behavior of the volumetric flux obtained by the modified membranes with $\mathrm{P}(\mathrm{SSNa})$ and $\mathrm{P}(\mathrm{AA})$ networks. The obtained low values of water flux show high resistances in the MAA2 and MSSNa2 samples because these samples possess more compact polymer networks, which were synthesized with a high concentration of the MBA crosslinking monomer. 
However, the polymer networks for the MSSNa1 and MAA1 samples are lower in concentration than those of the MAA2 and MSSNa2 samples because they let more water flow through. The modified samples achieved low values for the volumetric flux in comparison with that obtained for the MPP sample.

The same effect can be seen by comparing the MGN1, MCIV1, MGN2, and MCIV2 samples with the MPP sample (see Figure 3). However, these samples possess $\mathrm{P}(\mathrm{ClVBTA})$ and $\mathrm{P}(\mathrm{GMA}-\mathrm{NMG})$ networks. This simple test confirms that the membranes treated with the functional monomer impregnation process and polymerization changed their internal structures $[29,30]$.

A more quantitative approach to confirming the structural modification of the commercial PP membranes is achieved with the $\% \Delta \mathrm{G}_{\mathrm{m}}$. If the MBA concentration increases, then the mass quantity of the ion exchange IPN is higher, but a limit is established by the size of the pores in the commercial MPP. For MSSNa1, MSSNa2, MAA1 and MAA2, this relationship is linear (see Figure 3).
MSSNa1 and MAA1 achieve very similar values. These results are attributed to the mass quantity of the ion exchange IPNs, which increases and do not swell freely, limiting the passage of water through the pores (MSSNa2 and MAA2) (see Figure 3). This information shows that the porous commercial PP membranes are filled by the crosslinked ion exchange IPN. It is possible that the free radical polymerization process of AA and GMA-NMG was faster than that of the SSNa and ClVBTA monomers because AA and GMA-NMG are highly hydrophilic, more soluble in the reaction media and possess short hydrocarbon chains in comparison with those of SSNa and ClVBTA.

Through a physical method of characterization of modified membrane materials such as mass variation and the ability to absorb water (hydrophilic properties), it has been found that the polymerization reaction occurred inside the structure of the porous membranes of PP. Therefore, the next step is to perform the microstructural characterization and determine the distribution of the ion exchange material in the polypropylene membranes using the SEM technique.

SEM analysis
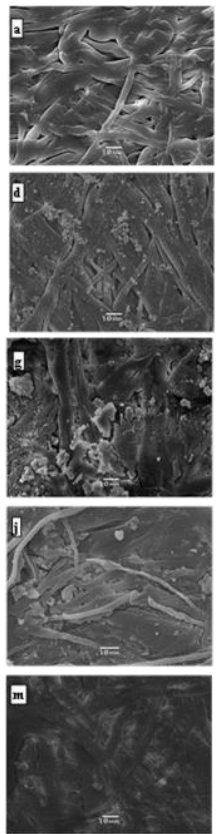
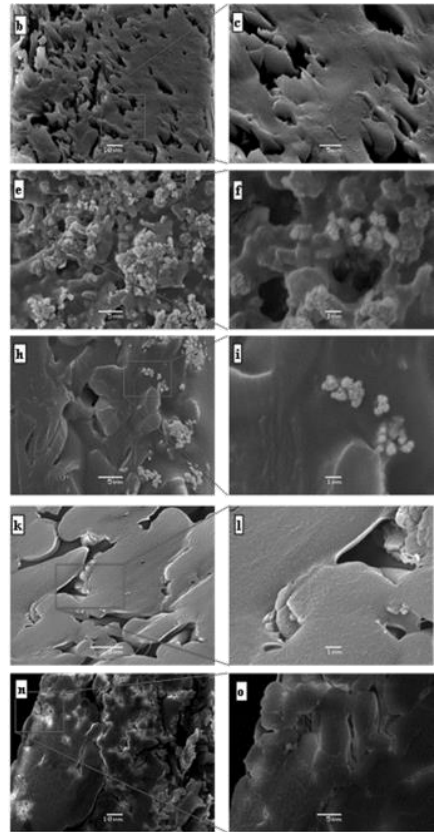

Figure 4. SEM images. MPP (a. Surface face to $10 \mu \mathrm{m}, \times 300$. b. Cross-section area to $10 \mu \mathrm{m}, \times 300$. c. Cross-section area near the superficial face to $5 \mu \mathrm{m}$ and $\times 3000$ ). MAA2, a modified membrane with P(AA) networks (d. Surface face to $10 \mu \mathrm{m}$ and $\times 300$. e. Cross-section area to $5 \mu \mathrm{m}$ and $\times 3000$. f. Cross-section area near to the surface face to $1 \mu \mathrm{m}$, and $\times 3000$ ). MSSNa2, a modified membrane with P(SSNa) networks (g. Surface face to $10 \mu \mathrm{m}$ and $\times 300$. h. Cross-section area to $5 \mu \mathrm{m}$ and $\times 3000$. i. Cross-section area near the surface to $1 \mu \mathrm{m}$ and $\times 3000)$. MNG2, a modified membrane with P(GMA-NMG) networks (j. surface face to $10 \mu \mathrm{m}$ and $\times 300$. k. Cross-section area to $5 \mu \mathrm{m}$ and $\times 3000$. 1. Cross-section area near the surface face to $1 \mu \mathrm{m}$ and $\times 3000)$. MClV2, a modified membrane with P(ClVBTA) networks (m. Superficial face to $10 \mu \mathrm{m}$ and $\times 300$. $\mathrm{n}$. Cross-section area to $10 \mu \mathrm{m}$ and $\times 3000$. o. Cross-section area near the surface face to $5 \mu \mathrm{m}$ and $\times 3000$ ).

The microstructure changes in the ion exchange IPNs membranes were analyzed and compared with the structure of the unmodified commercial PP membrane by SEM. In the case of the commercial PP, the anisotropic structure of the membrane is observable (see Figure 4 (a)). Furthermore, the PP membrane possesses a high density of intertwined PP fibers in the structure, a smooth superficial aspect and a non-uniform pore distribution (see Figure 4 (b) and Figure 4 (c)).

In comparison with the MPP sample, the MAA2 sample has two solid phases in its microstructure (see Figure 4 (d)). The P(AA) ion exchange resin phase formed with an irregular form, and this material covers the two surface faces of the sample. The cross-section area shows that the ion exchange P(AA) networks are covering all surfaces of the internal PP fibers with a granular material form (see Figure 4 (e) and Figure 4 (f)).

Additionally, the MSSNa2 sample achieves the same result as MAA2 with the two solid phases (see Figure $4(\mathrm{~g})$ ). The main difference between MSSNa2 and MAA2 is the size of the ion exchange IPN adding to the surface of the PP fibers. In the face side, the $\mathrm{P}(\mathrm{SSNa})$ networks are covering the areas of the superficial pores, decreasing the average pores size, while MAA2 can preserve the average size of the initial pores.
The cross-section area of MSSNa (see Figure 4 (h) and Figure 4 (i)) has an internal microstructure with a high density of the compact PP fibers; it is only possible to add a low concentration of the ion exchange $\mathrm{P}(\mathrm{SSNa})$ network to the pore walls.

The ion exchange $\mathrm{P}(\mathrm{GMA}-\mathrm{NMG})$ network of MNG2 presents a granular form, which can fill out the superficial pores and cover the PP fibers on the two faces (see Figure $4(\mathrm{j})$ ). The size and distribution is very similar to those of the SSNa sample. Furthermore, MNG2 exhibits an internal microstructure with a high density of the compact PP fibers. However, the ion exchange IPNs fills out the void spaces, adhering to the wall of the pores (see Figure 4 (k) and Figure 4 (1)).

For the MCIV2 sample, the ion exchange P(CIVBTA) IPN is covering all PP fiber surfaces on both faces, similar to a paint (see Figure $4(\mathrm{~m})$ ). The $\mathrm{P}(\mathrm{CIVBTA})$ IPN is not modified considerably in comparison to the IPNs of MSSNa2 and MNG2. From the cross-section area of the MCIV2 sample, the ion exchange P(CIVBTA) IPN only coats the pore walls but does not fill out the void spaces of the internal pores (see Figure 4 (n) and Figure 4 (o)).

These results indicate changes in the microstructural homogeneity compared with that of the unmodified PP membrane. For the modification of commercial microporous PP membranes, previous research has reported results similar to those of the SEM analysis. 
For example, the activation of the surface of a PP membrane was achieved by grafting polyacrylic acid followed by grafting titanium dioxide $\left(\mathrm{TiO}_{2}\right)$ nanoparticles. The modified surface shows an agglomerated material adhered to the surface of the PP, which contrasts the surface of the unmodified PP membrane, and the main goal was to improve the hydrophilicity of the surface [31]. PP was the host membrane for preparation of an anion exchange pore-filled membrane, where the SEM analysis showed a final homogeneous microstructure covering all surfaces. These membranes were used in the Donnan dialysis process for the recovery of $\mathrm{Au}(\mathrm{III})$ from aqua regia solutions of electronic waste [18]. Similar results were obtained when PP membranes were modified with three different biopolymers (chitosan, potato starch, and cellulose) because the biopolymers formed pores of heterogeneous size and increased the thickness of the fibers in the modified membrane; whereas, the main application was in the removal of metal ions $[32,33]$. The presence of ion exchange material supported inside the PP membranes was verified through SEM characterization. For this reason, the next step is to evaluate the behavior of the fixed charges of the ion exchange material supported within the structure of the PP membranes used in

\section{Charge density properties}

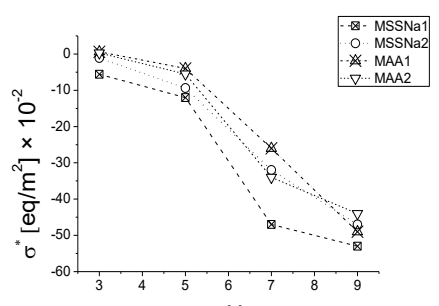

a

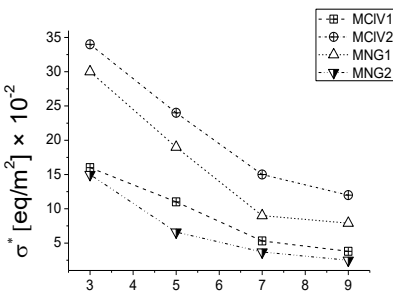

b electrokinetic studies.

neutralize the fixed charges. At all times, the charge density values depend on the ion exchange IPN concentration, the wetting capacity and $\mathrm{pH}$ value [36]

\section{Transport properties by Donnan dialysis}

The Donnan dialysis method was used to analyze the transport capacity of the modified membranes with $\mathrm{P}(\mathrm{SSNa})$ and $\mathrm{P}(\mathrm{AA})$ networks for $\mathrm{Cr}(\mathrm{III})$ ions. At $\mathrm{pH}$ 3.0 and room temperature, the $\mathrm{Cr}(\mathrm{III})$ ions have a speciation such as $\mathrm{CrOH}^{2+}$ or $\mathrm{Cr}(\mathrm{OH})_{2}{ }^{+}$at $6.4 \times 10^{-3} \mathrm{~mol} \mathrm{~L}^{-1}$ and $8.0 \times 10^{-3} \mathrm{~mol} \mathrm{~L}^{-1}[37]$
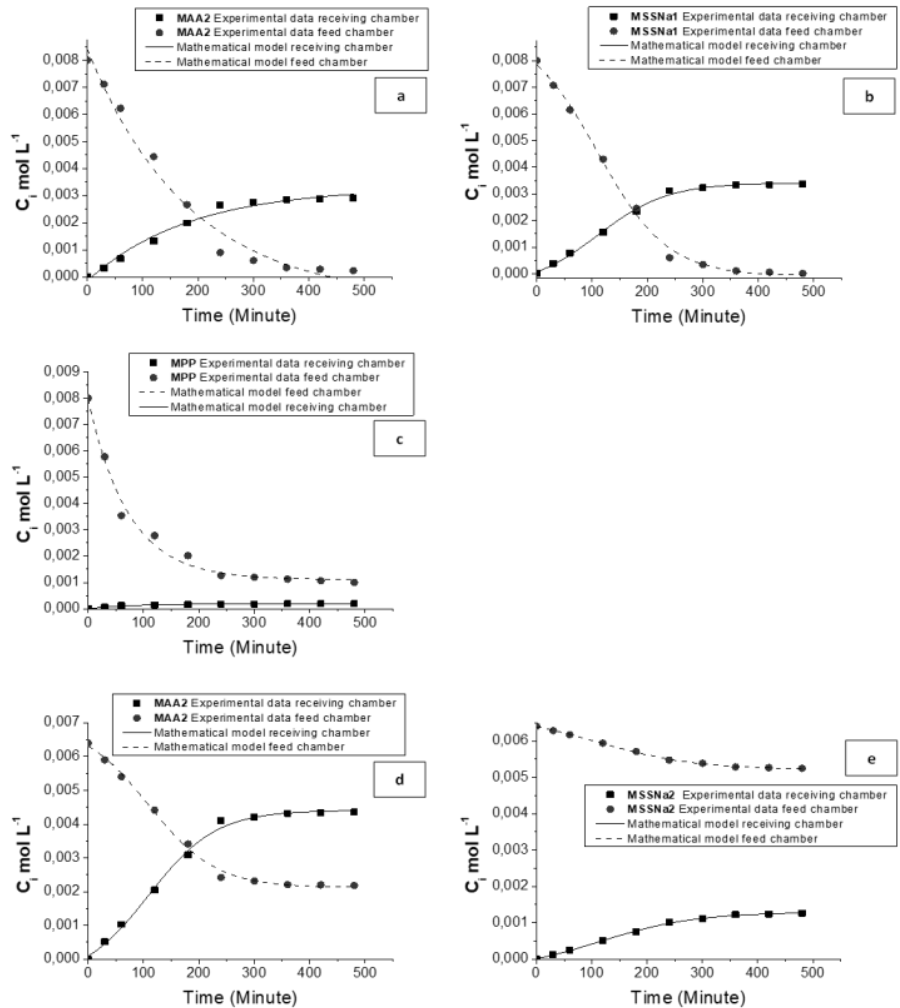

ion exchange IPN membrane allows control of the absorption rate, wetting and mobility of ions [35]. The charge density values are attributed to the fixed charge potential difference between the functional groups of the IPN and the mobile ionic charges in the absorption layer. Figure 5(a) shows the charge density profile of the ion exchange $\mathrm{P}(\mathrm{SSNa})$ and $\mathrm{P}(\mathrm{AA})$ IPN membrane samples with respect to different $\mathrm{pH}$ values. If the $\mathrm{pH}$ value is 3.0 , the charge density values are less negative because of the excess $\mathrm{H}^{+}$ions and the $\mathrm{Na}^{+}$counterions competing to neutralize the fixed charge. Furthermore, the chelating-ion exchange P(AA) IPNs (MAA1 and MAA2) show that at low $\mathrm{pH}$ values, they have an uncharged structure. However, at high $\mathrm{pH}$ values, the carboxylic side groups are negatively charged. MSSNa1 and MSSNa2 in the entire $\mathrm{pH}$ range have negative charge densities. These membranes (MSSNa1, MSSNa2, MAA1, and MAA2) achieve the most-negative charge density values when the $\mathrm{pH}$ is 9.0. At basic $\mathrm{pH}$ values, the excess $\mathrm{OH}^{-}$ions repel the groups fixed to the membrane sample and compete with the fixed groups for the $\mathrm{Na}^{+}$counter ions. The surfaces of the ion exchange membranes and the pore walls are negative electrically charged, and their conformation is that of an extended structure.

Figure 5(b) shows the charge density profiles of the ion exchange P(ClVBTA) and $\mathrm{P}(\mathrm{GMA}-\mathrm{NMG}) \mathrm{IPN}$ membrane samples with respect to different $\mathrm{pH}$ values. MCIV1, MCIV2, MNG1, and MNG2 show the reverse behavior in terms of the charge density profile when compared to that of the ion exchange $\mathrm{P}(\mathrm{SSNa})$ and P(AA) IPNs, due to the superficial positive charge. These membranes achieve the most positive charge density values when the $\mathrm{pH}$ is 3.0 . When the $\mathrm{pH}$ value is 3.0, the charge density values become highly positive for the MCIV1, MCIV2, MNG1, and MNG2 samples. At acidic $\mathrm{pH}$, the excess $\mathrm{H}^{+}$ions repel the quaternary ammonium groups fixed on the membrane sample and compete with the fixed groups for the $\mathrm{Cl}^{-}$counter ions. In addition, at low $\mathrm{pH}$ values, the chelating-ion exchange $\mathrm{P}(\mathrm{GMA}-\mathrm{NMG}) \mathrm{IPNs}$ (MNG1 and MNG2) presents a positively charged structure; however, at high $\mathrm{pH}$ values, the $N$-methyl-Dglucamine side groups are uncharged. MClV1 and MClV2 have negative charge densities over the whole $\mathrm{pH}$ range. In addition, for the MCIV1, MCIV2, MNG1, and MNG2 samples, at a $\mathrm{pH}$ of 9.0, the positive charge density values decrease because of the presence of excess $\mathrm{OH}^{-}$ions and the $\mathrm{Cl}^{-}$counter ions competing to

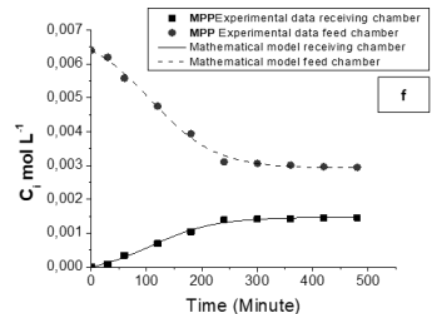

Figure 6. Experimental data for the $\mathrm{Cr}(\mathrm{III})$ ion concentrations in both phases (feed and receiving) at $\mathrm{pH}$ 3.0, using different $\mathrm{Cr}$ (III) concentrations, and fitted to the mathematical model. For $[\mathrm{Cr}(\mathrm{III})]=8.0 \times 10^{-3} \mathrm{~mol} \mathrm{~L}^{-1}$, using a. MAA2, b. MSSNa1, and c. MPP. For $[\mathrm{Cr}(\mathrm{III})]=6.4 \times 10^{-3} \mathrm{~mol} \mathrm{~L}^{-1}$, using: d. MAA2, e. MSSNa2, and f. MPP.

Figure 6 shows the transport profiles for both the feed and receiving chambers, when the $\mathrm{Cr}$ (III) ions were studied at $\mathrm{pH}$ 3.0. In these graphics, the experimental data and the mathematical model of the fit polynomial are provided together. Under both experimental conditions, the MPP was used as the comparison parameter or zero point because it does not contain chelating-ion exchange interpenetrating polymer networks. The Donnan equilibrium was achieved at 300 min. Under both experimental conditions, MAA2 (see Figure 6 (a) and (d)) does not produce electrostatic interactions with the $\mathrm{Cr}$ (III) species because the fixed carboxylate groups are protonated all the time and the replacement of the $\mathrm{Cr}(\mathrm{III})$ ions is poor.

The increase in $\operatorname{Cr}(\mathrm{III})$ ions in the receiving phase is due to the Donnan exclusion principle. Furthermore, this transport process using the fixed carboxylate groups is balanced by the pumping of $\mathrm{Na}^{+}$and $\mathrm{H}^{+}$ions that move in the counter direction. In general, these results depend on the $\mathrm{Cr}$ (III) ion concentration, fixed functional group, and degree of crosslinking in the supported PP membranes. 
Table 1 displays the $\beta_{\mathrm{i}}$ coefficients for the polynomial fits. All $\mathrm{R}^{2}$ values are close to 1 . The concentration polarization effect was neglected because of the sufficiently high stirring speed in each cell chamber. Table 2 displays the total rates of diffusion of the $\mathrm{Cr}$ (III) ions from the feed phase to the receiving phase as a function of the $\beta_{\mathrm{i}}$ coefficients. This mathematical model achieves a good fit to the experimental data with respect to time and can be used as a tool to predict the evolution of $\mathrm{Cr}(\mathrm{III})$ ion concentration in both phases while using the $\mathrm{P}(\mathrm{SSNa})$ and $\mathrm{P}(\mathrm{AA})$ interpenetrating polymer networks. The mathematical model can be seen in the Figure 6.

Table 1. Values of the constants of the order n polynomial mathematical model fit using the concentration experimental data of the $\mathrm{Cr}(\mathrm{III})$ ions.

\begin{tabular}{|c|c|c|c|c|c|c|c|}
\hline \multicolumn{8}{|c|}{$C_{\text {Feed }}=\beta_{0}+\beta_{1} t+\beta_{2} t^{2}+\beta_{3} t^{3}+\beta_{4} t^{4}$} \\
\hline Experimental condition & Sample & $\mathbf{R}^{2}$ & $\overline{\beta_{0}}$ & $\beta_{1}$ & $\beta_{2}$ & $\boldsymbol{\beta}_{3}$ & $\boldsymbol{\beta}_{4}$ \\
\hline \multirow{10}{*}{$\begin{array}{c}{[\mathrm{Cr}(\mathrm{III})]} \\
6.4 \times 10^{-3} \mathrm{~mol} \mathrm{~L}^{-1}\end{array}$} & MSSNa2 & 0.97 & $7.52 \times 10^{-3}$ & 0 & 0 & $-3.86 \times 10^{-10}$ & $6.79 \times 10^{-13}$ \\
\hline & MAA2 & 0.99 & $7.93 \times 10^{-3}$ & $-2.09 \times 10^{-5}$ & $-1.40 \times 10^{-7}$ & $6.07 \times 10^{-10}$ & $-6.13 \times 10^{-13}$ \\
\hline & MPP & 0.97 & $7.53 \times 10^{-3}$ & $-6.20 \times 10^{-5}$ & $-1.97 \times 10^{-7}$ & $-2.02 \times 10^{-10}$ & 0 \\
\hline & & \multicolumn{6}{|c|}{$C_{\text {Receiving }}=\beta_{0}+\beta_{1} t+\beta_{2} t^{2}+\beta_{3} t^{3}+\beta_{4} t^{4}$} \\
\hline & MSSNa2 & 0.97 & $1.13 \times 10^{-4}$ & 0 & 0 & $1.06 \times 10^{-10}$ & $-1.87 \times 10^{-13}$ \\
\hline & MAA1 & 0.99 & $2.21 \times 10^{-4}$ & 0 & $1.45 \times 10^{-7}$ & $-5.20 \times 10^{-10}$ & $5.16 \times 10^{-13}$ \\
\hline & MAA2 & 0.99 & $2.52 \times 10^{-5}$ & $7.80 \times 10^{-6}$ & $5.23 \times 10^{-8}$ & $-2.27 \times 10^{-10}$ & $2.29 \times 10^{-13}$ \\
\hline & MPP & 0.97 & $1.28 \times 10^{-5}$ & $1.67 \times 10^{-6}$ & $-5.32 \times 10^{-9}$ & $5.45 \times 10^{-12}$ & 0 \\
\hline & & \multicolumn{6}{|c|}{$C_{\text {Feed }}=\beta_{0}+\beta_{1} t+\beta_{2} t^{2}+\beta_{3} t^{3}+\beta_{4} t^{4}$} \\
\hline & Sample & $\mathbf{R}^{2}$ & $\beta_{0}$ & $\beta_{1}$ & $\beta_{2}$ & $\beta_{3}$ & $\beta_{4}$ \\
\hline \multirow{7}{*}{$\begin{array}{c}{[\mathrm{Cr}(\mathrm{III})]} \\
8.0 \times 10^{-3} \mathrm{~mol} \mathrm{~L}^{-1}\end{array}$} & & \multicolumn{6}{|c|}{$C_{\text {Receiving }}=\beta_{0}+\beta_{1} t+\beta_{2} t^{2}+\beta_{3} t^{3}+\beta_{4} t^{4}$} \\
\hline & Sample & $\mathbf{R}^{2}$ & $\beta_{0}$ & $\beta_{1}$ & $\beta_{2}$ & $\beta_{3}$ & $\beta_{4}$ \\
\hline & MPP & 0.99 & $-7.37 \times 10^{-5}$ & $7.34 \times 10^{-6}$ & 0 & $-4.02 \times 10^{-11}$ & $4.60 \times 10^{-14}$ \\
\hline & MSSNa1 & 0.99 & $-1.14 \times 10^{-4}$ & $2.05 \times 10^{-5}$ & 0 & $-1.02 \times 10^{-10}$ & $1.09 \times 10^{-13}$ \\
\hline & MSSNa2 & 0.99 & $-1.67 \times 10^{-5}$ & $4.72 \times 10^{-6}$ & 0 & $-1.29 \times 10^{-11}$ & $7.96 \times 10^{-15}$ \\
\hline & MAA1 & 0.99 & $4.46 \times 10^{-5}$ & $9.45 \times 10^{-6}$ & $8.08 \times 10^{-8}$ & $-3.40 \times 10^{-10}$ & $-3.36 \times 10^{-13}$ \\
\hline & MAA2 & 0.99 & $-1.13 \times 10^{-4}$ & $2.08 \times 10^{-5}$ & 0 & $-1.04 \times 10^{-10}$ & $-1.08 \times 10^{-13}$ \\
\hline
\end{tabular}

Table 2. Values of the constants of the mathematical model fit using the experimental data of the $\mathrm{Cr}(\mathrm{III})$ ions.

\begin{tabular}{|c|c|c|c|c|c|}
\hline \multicolumn{6}{|c|}{$\frac{d C_{\text {Feed }}}{d t}=\beta_{1}+\left(2 * \beta_{2}\right) t+\left(3 * \beta_{3}\right) t^{2}+\left(4 * \beta_{4}\right) t^{3}$} \\
\hline Experimental condition & Sample & $\beta_{1}$ & $\left(2 * \boldsymbol{\beta}_{2}\right)$ & $\left(3 * \boldsymbol{\beta}_{3}\right)$ & $\left(4 * \beta_{4}\right)$ \\
\hline \multirow{12}{*}{$\begin{array}{c}{[\mathrm{Cr}(\mathrm{III})]} \\
8.0 \times 10^{-3} \mathrm{~mol} \mathrm{~L}^{-1}\end{array}$} & MSSNa1 & $2.13 \times 10^{-5}$ & $-3.03 \times 10^{-7}$ & $1.97 \times 10^{-9}$ & $-2.66 \times 10^{-12}$ \\
\hline & MSSNa2 & 0 & 0 & $-1.16 \times 10^{-9}$ & $2.72 \times 10^{-12}$ \\
\hline & MAA1 & 0 & $-6.47 \times 10^{-7}$ & $3.49 \times 10^{-9}$ & $-4.61 \times 10^{-12}$ \\
\hline & MAA2 & $2.09 \times 10^{-5}$ & $-2.80 \times 10^{-7}$ & $1.82 \times 10^{-9}$ & $-2.45 \times 10^{-12}$ \\
\hline & MPP & $-6.20 \times 10^{-5}$ & $3.93 \times 10^{-7}$ & $-6.05 \times 10^{-10}$ & 0 \\
\hline & & \multicolumn{4}{|c|}{$\frac{d C_{\text {Receiving }}}{d t}=\beta_{1}+\left(2 * \beta_{2}\right) t+\left(3 * \beta_{3}\right) t^{2}+\left(4 * \beta_{4}\right) t^{3}$} \\
\hline & Sample & $\beta_{1}$ & $\left(2 * \boldsymbol{\beta}_{2}\right)$ & $\left(3 * \boldsymbol{\beta}_{3}\right)$ & $\left(\mathbf{4} * \boldsymbol{\beta}_{4}\right)$ \\
\hline & MSSNa1 & $9.00 \times 10^{-6}$ & $1.28 \times 10^{-7}$ & $-8.31 \times 10^{-10}$ & $1.12 \times 10^{-12}$ \\
\hline & MSSNa2 & 0 & 0 & $3.18 \times 10^{-10}$ & $-7.46 \times 10^{-13}$ \\
\hline & MAA1 & 0 & $2.87 \times 10^{-7}$ & $-1.56 \times 10^{-9}$ & $2.06 \times 10^{-12}$ \\
\hline & MAA2 & $7.80 \times 10^{-6}$ & $1.05 \times 10^{-7}$ & $-6.80 \times 10^{-10}$ & $9.15 \times 10^{-13}$ \\
\hline & MPP & $1.67 \times 10^{-6}$ & $-1.06 \times 10^{-8}$ & $1.63 \times 10^{-11}$ & 0 \\
\hline & & \multicolumn{4}{|c|}{$\frac{d C_{\text {Feed }}}{d t}=\beta_{1}+\left(2 * \beta_{2}\right) t+\left(3 * \beta_{3}\right) t^{2}+\left(4 * \beta_{4}\right) t^{3}$} \\
\hline & Sample & $\beta_{1}$ & $\left(2 * \boldsymbol{\beta}_{2}\right)$ & $\left(3 * \boldsymbol{\beta}_{3}\right)$ & $\left(\mathbf{4} * \boldsymbol{\beta}_{4}\right)$ \\
\hline \multirow{12}{*}{$\begin{array}{c}\operatorname{Cr}(\mathrm{III})] \\
6.4 \times 10^{-3} \mathrm{~mol} \mathrm{~L}^{-1}\end{array}$} & MPP & $-1.74 \times 10^{-5}$ & 0 & $2.86 \times 10^{-10}$ & $-1.20 \times 10^{-10}$ \\
\hline & MSSNa1 & $-1.99 \times 10^{-5}$ & 0 & $2.97 \times 10^{-10}$ & $-3.06 \times 10^{-10}$ \\
\hline & MSSNa2 & $-4.32 \times 10^{-6}$ & 0 & $3.53 \times 10^{-11}$ & $-3.86 \times 10^{-11}$ \\
\hline & MAA1 & $-9.31 \times 10^{-6}$ & $-1.59 \times 10^{-7}$ & $1.00 \times 10^{-9}$ & $-1.02 \times 10^{-9}$ \\
\hline & MAA2 & $-2.01 \times 10^{-5}$ & 0 & $3.02 \times 10^{-10}$ & $-3.11 \times 10^{-10}$ \\
\hline & & \multicolumn{4}{|c|}{$\frac{d C_{\text {Receiving }}}{d t}=\beta_{1}+\left(2 * \beta_{2}\right) t+\left(3 * \beta_{3}\right) t^{2}+\left(4 * \beta_{4}\right) t^{3}$} \\
\hline & Sample & $\beta_{1}$ & $\left(2 * \boldsymbol{\beta}_{2}\right)$ & $\left(3 * \boldsymbol{\beta}_{3}\right)$ & $\left(\mathbf{4} * \boldsymbol{\beta}_{\mathbf{4}}\right)$ \\
\hline & MPP & $7.33 \times 10^{-6}$ & 0 & $-1.20 \times 10^{-10}$ & $1.84 \times 10^{-13}$ \\
\hline & MSSNa1 & $2.05 \times 10^{-5}$ & 0 & $-3.06 \times 10^{-10}$ & $4.37 \times 10^{-13}$ \\
\hline & MSSNa2 & $4.72 \times 10^{-6}$ & 0 & $-3.86 \times 10^{-11}$ & $3.18 \times 10^{-14}$ \\
\hline & MAA1 & $9.45 \times 10^{-6}$ & $1.62 \times 10^{-7}$ & $-1.02 \times 10^{-9}$ & $-1.35 \times 10^{-12}$ \\
\hline & MAA2 & $2.08 \times 10^{-5}$ & 0 & $-3.11 \times 10^{-10}$ & $-4.32 \times 10^{-13}$ \\
\hline
\end{tabular}


In the case of $\mathrm{Cr}(\mathrm{VI})$ ions, the ion species depend on the concentration in an acid environment ( $\mathrm{pH}$ 3.0) and primarily form $\mathrm{Cr}_{2} \mathrm{O}_{7}^{2-}$ and $\mathrm{HCrO}_{4}^{-}$, while at pH 9.0, most of the $\mathrm{Cr}(\mathrm{VI})$ ions are $\mathrm{CrO}_{4}{ }^{2-}$. The modified membranes used in this case are $\mathrm{P}(\mathrm{ClVBTA})$ and $\mathrm{P}(\mathrm{GMA}-\mathrm{NMG})$ networks.
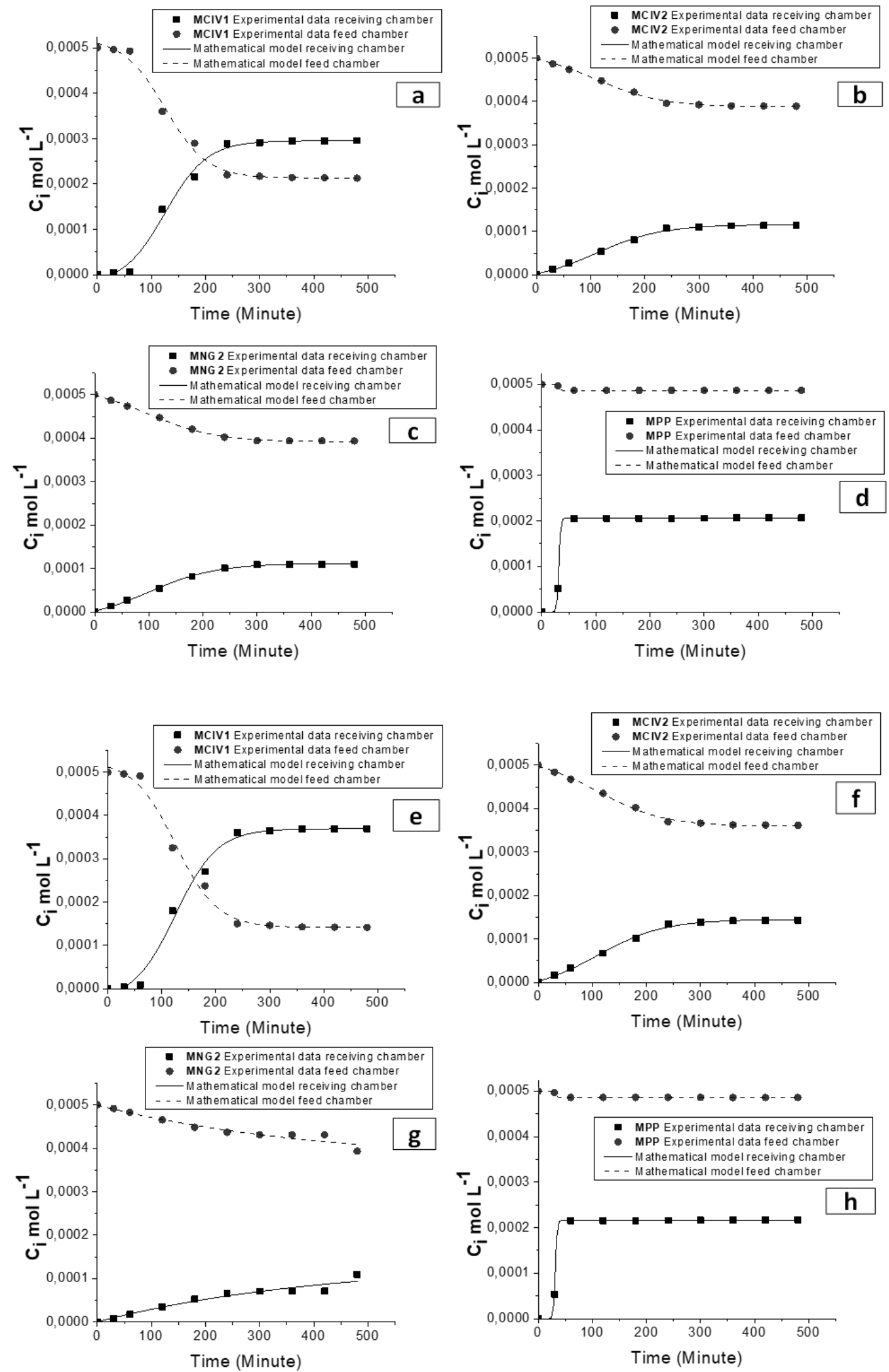

Figure 7. Experimental data for the $\mathrm{Cr}(\mathrm{VI})$ ions concentrations in both phases (feed and receiving) at $\mathrm{pH} 3.0$ and 9.0 , and the data fitted to the mathematical model. For $[\mathrm{Cr}(\mathrm{VI})]=5.0 \times 10^{-4} \mathrm{~mol} \mathrm{~L}^{-1}$ at $\mathrm{pH} 3.0$, using: a. MClV1, b. MClV1, c. MNG2, and d. MPP. For $[\mathrm{Cr}(\mathrm{VI})]=5.0 \times 10^{-4} \mathrm{~mol} \mathrm{~L}^{-1}$ at pH 9.0, using: e. MClV1, f. MClV2, g. MNG2, and h. MPP. 
Figure 7 shows the profiles of both the feed and receiving chambers when the $\mathrm{Cr}(\mathrm{VI})$ ions are studied at $\mathrm{pH} 3.0$ and $\mathrm{pH}$ 9.0. Additionally, under both experimental conditions, the MPP is used as the comparison parameter. For the test at $\mathrm{pH}$ 3.0, the Donnan equilibrium is achieved at $200 \mathrm{~min}$ for MClV1 (see Figure 7 (a)) and MClV2 (see Figure 7 (b)), while that of MNG2 is achieved at 300 min (see Figure 7 (c)).

Furthermore, the $\mathrm{P}(\mathrm{GMA}-\mathrm{NMG})$ networks at $\mathrm{pH} 3.0$ have a positive charge due to the nitrogen of the NMG. The charge is similar to the quaternary ammonium of the $\mathrm{P}(\mathrm{ClVBTA})$ networks and produces a potential gradient. The retention effect of MClV2 and MNG2 towards the $\mathrm{Cr}(\mathrm{VI})$ ion species is high. Moreover, Figure 7 (d) shows the separation behavior of the ions when an MPP is used without any modification. This membrane is used for comparison. In this image can be seen that although the membrane is not modified and it is highly hydrophobic.

Nevertheless, at $\mathrm{pH}$ 9.0, the retention effect decreases for every sample membrane. The decreasing order for the ion exchange transport capacity is: MClV1 (see Figure 7 (e)) > MClV2 (see Figure 7 (f)) > MNG2 (see Figure 7 $(\mathrm{g})$ ). The hydroxyl ions compete with the $\mathrm{Cr}(\mathrm{VI})$ ions and $\mathrm{Cl}^{-}$ions for the positively charged fixed groups in the membrane, and this disturbance of the
Donnan potential brings about the high transport of the $\mathrm{Cr}(\mathrm{VI})$ ions towards the receiving phase.

The sorption of $\mathrm{Cr}(\mathrm{VI}), \mathrm{Na}^{+}, \mathrm{Cl}^{-}, \mathrm{H}^{+}$, and $\mathrm{OH}^{-}$species suggests that some of these species can pass to the opposite side against the stoichiometry predicted by the chelating-ion exchange reaction.

Table 3 displays the $\beta_{\mathrm{i}}$ coefficients for the polynomial fits of the $\mathrm{Cr}(\mathrm{VI})$. All the $\mathrm{R}^{2}$ values are close to 1 . Table 4 displays the total diffusion rates of the $\mathrm{Cr}(\mathrm{VI})$ ions from the feed phase to the receiving phase as a function of the $\beta_{\mathrm{i}}$ coefficients When selecting the n-order of the polynomial equation, it was considered that, if the selection of the n-order is low, then the polynomial fit does not represent the trend of the experimental data and an abundance of data will be excluded (for example order 2 or 3 ). However, if the selection of the n-order is high, the curve fit presents crests and valleys in most of the data. The above described behavior produces mistakes when calculating $\mathrm{dC}_{\mathrm{i}} / \mathrm{dt}$. The mathematical model can be seen in the Figure 7. This mathematical model achieves a good fit to the experimental data with respect to time, and this model can used as a tool to predict the evolution of $\mathrm{Cr}(\mathrm{VI})$ concentration in both phases using the $\mathrm{P}(\mathrm{ClVBTA})$ and $\mathrm{P}(\mathrm{GMA}-\mathrm{NMG})$ interpenetrating polymer networks.

Table 3. Values of the constants of the order n polynomial mathematical model fit using the concentration experimental data of the $\mathrm{Cr}(\mathrm{VI})$ ions.

\begin{tabular}{|c|c|c|c|c|c|c|c|c|c|c|}
\hline \multicolumn{11}{|c|}{$C_{F e e d}=\beta_{0}+\beta_{1} t+\beta_{2} t^{2}+\beta_{3} t^{3}+\beta_{4} t^{4}+\beta_{5} t^{5}+\beta_{6} t^{6}+\beta_{7} t^{7}$} \\
\hline $\begin{array}{l}\text { Experimental } \\
\text { condition }\end{array}$ & Sample & $\mathbf{R}^{2}$ & $\boldsymbol{\beta}_{0}$ & $\boldsymbol{\beta}_{1}$ & $\boldsymbol{\beta}_{2}$ & $\boldsymbol{\beta}_{3}$ & $\boldsymbol{\beta}_{4}$ & $\boldsymbol{\beta}_{5}$ & $\boldsymbol{\beta}_{6}$ & $\boldsymbol{\beta}_{7}$ \\
\hline \multirow{12}{*}{$\begin{array}{c}{[\mathrm{Cr}(\mathrm{VI})]} \\
5.0 \times 10^{-4} \mathrm{~mol} \mathrm{~L}^{-1} \\
\text { pH } 3.0\end{array}$} & MPP & 0.97 & $9.99 \times 10^{-5}$ & 0 & 0 & $-1.39 \times 10^{-13}$ & $2.33 \times 10^{-16}$ & 0 & 0 & 0 \\
\hline & MClV1 & 0.99 & $1.00 \times 10^{-4}$ & 0 & $-1.39 \times 10^{-9}$ & $2.48 \times 10^{-10}$ & $-1.77 \times 10^{-12}$ & $5.99 \times 10^{-15}$ & $-9.68 \times 10^{-18}$ & $5.99 \times 10^{-21}$ \\
\hline & MClV2 & 0.99 & $1.01 \times 10^{-4}$ & $-3.48 \times 10^{-7}$ & 0 & $4.54 \times 10^{-11}$ & $-4.35 \times 10^{-13}$ & $1.65 \times 10^{-15}$ & $-2.79 \times 10^{-18}$ & $1.76 \times 10^{-21}$ \\
\hline & MNG1 & 0.99 & $1.02 \times 10^{-4}$ & $-2.76 \times 10^{-7}$ & 0 & $1.02 \times 10^{-12}$ & 0 & 0 & $-3.06 \times 10^{-21}$ & 0 \\
\hline & MNG2 & 0.99 & $1.00 \times 10^{-4}$ & $-3.08 \times 10^{-7}$ & $3.17 \times 10^{-7}$ & 0 & $2.51 \times 10^{-14}$ & $-9.91 \times 10^{-17}$ & $8.51 \times 10^{-20}$ & 0 \\
\hline & & \multicolumn{9}{|c|}{$C_{\text {Receiving }}=\beta_{0}+\beta_{1} t+\beta_{2} t^{2}+\beta_{3} t^{3}+\beta_{4} t^{4}+\beta_{5} t^{5}+\beta_{6} t^{6}+\beta_{7} t^{7}$} \\
\hline & Sample & $\mathbf{R}^{2}$ & $\boldsymbol{\beta}_{0}$ & $\beta_{1}$ & $\boldsymbol{\beta}_{2}$ & $\boldsymbol{\beta}_{3}$ & $\boldsymbol{\beta}_{4}$ & $\beta_{5}$ & $\beta_{6}$ & $\boldsymbol{\beta}_{7}$ \\
\hline & MPP & 0.97 & $2.06 \times 10^{-8}$ & 0 & 0 & $1.23 \times 10^{-13}$ & $-2.07 \times 10^{-16}$ & 0 & 0 & 0 \\
\hline & MClV1 & 0.99 & $-4.80 \times 10^{-8}$ & 0 & $1.43 \times 10^{-8}$ & $-2.55 \times 10^{-10}$ & $1.82 \times 10^{-12}$ & $5.99 \times 10^{-15}$ & $9.97 \times 10^{-18}$ & $-6.17 \times 10^{-21}$ \\
\hline & MClV2 & 0.99 & $-6.76 \times 10^{-7}$ & $3.59 \times 10^{-7}$ & 0 & $-4.67 \times 10^{-11}$ & $4.48 \times 10^{-13}$ & $1.65 \times 10^{-15}$ & $2.87 \times 10^{-18}$ & $-1.81 \times 10^{-21}$ \\
\hline & MNG1 & 0.99 & $-1.55 \times 10^{-6}$ & $2.84 \times 10^{-7}$ & 0 & $1.05 \times 10^{-12}$ & 0 & 0 & $3.16 \times 10^{-21}$ & 0 \\
\hline & MNG2 & 0.99 & $-6.78 \times 10^{-8}$ & $-6.79 \times 10^{-8}$ & 0 & 0 & $-2.59 \times 10^{-14}$ & $-8.91 \times 10^{-17}$ & $-8.77 \times 10^{-20}$ & 0 \\
\hline & & \multicolumn{9}{|c|}{$C_{F e e d}=\beta_{0}+\beta_{1} t+\beta_{2} t^{2}+\beta_{3} t^{3}+\beta_{4} t^{4}+\beta_{5} t^{5}+\beta_{6} t^{6}+\beta_{7} t^{7}$} \\
\hline & Sample & $\mathbf{R}^{2}$ & $\boldsymbol{\beta}_{0}$ & $\beta_{1}$ & $\boldsymbol{\beta}_{2}$ & $\beta_{3}$ & $\boldsymbol{\beta}_{4}$ & $\beta_{5}$ & $\beta_{6}$ & $\boldsymbol{\beta}_{7}$ \\
\hline \multirow{10}{*}{$\begin{array}{c}{[\mathrm{Cr}(\mathrm{VI})]} \\
5.0 \times 10^{-4} \mathrm{~mol} \mathrm{~L}^{-1} \\
\text { pH } 9.0\end{array}$} & MPP & 0.86 & $4.99 \times 10^{-4}$ & $-1.77 \times 10^{-7}$ & $6.73 \times 10^{-10}$ & $-7.59 \times 10^{-13}$ & 0 & 0 & 0 & 0 \\
\hline & MClV1 & 0.98 & $5.07 \times 10^{-4}$ & 0 & $-1.58 \times 10^{-8}$ & $4.42 \times 10^{-11}$ & 0 & $-6.35 \times 10^{-17}$ & 0 & 0 \\
\hline & MClV2 & 0.99 & $5.02 \times 10^{-4}$ & $-5.97 \times 10^{-7}$ & 0 & 0 & $6.44 \times 10^{-15}$ & 0 & $-1.61 \times 10^{-20}$ & 0 \\
\hline & MNG2 & 0.99 & $5.00 \times 10^{-4}$ & $-2.99 \times 10^{-7}$ & 0 & 0 & 0 & $1.85 \times 10^{-17}$ & $-3.37 \times 10^{-20}$ & 0 \\
\hline & & \multicolumn{9}{|c|}{$C_{\text {Receiving }}=\beta_{0}+\beta_{1} t+\beta_{2} t^{2}+\beta_{3} t^{3}+\beta_{4} t^{4}+\beta_{5} t^{5}+\beta_{6} t^{6}+\beta_{7} t^{7}$} \\
\hline & Sample & $\mathbf{R}^{2}$ & $\beta_{0}$ & $\beta_{1}$ & $\boldsymbol{\beta}_{2}$ & $\beta_{3}$ & $\beta_{4}$ & $\beta_{5}$ & $\beta_{6}$ & $\boldsymbol{\beta}_{7}$ \\
\hline & MPP & 0.86 & $1.29 \times 10^{-5}$ & $2.77 \times 10^{-6}$ & $-1.05 \times 10^{-8}$ & $1.19 \times 10^{-11}$ & 0 & 0 & 0 & 0 \\
\hline & MClV1 & 0.99 & $-7.61 \times 10^{-6}$ & 0 & $1.63 \times 10^{-8}$ & $-4.55 \times 10^{-11}$ & 0 & $1.19 \times 10^{-17}$ & 0 & 0 \\
\hline & MClV2 & 0.99 & $-1.98 \times 10^{-6}$ & $6.15 \times 10^{-7}$ & 0 & 0 & $-6.64 \times 10^{-15}$ & 0 & $1.66 \times 10^{-20}$ & 0 \\
\hline & MNG2 & 0.99 & $-4.64 \times 10^{-7}$ & $3.09 \times 10^{-7}$ & 0 & 0 & 0 & $-1.90 \times 10^{-17}$ & $3.48 \times 10^{-20}$ & 0 \\
\hline
\end{tabular}


Table 4. Values of the constants of the mathematical model fit using the experimental data of the $\mathrm{Cr}(\mathrm{III})$ ions.

\begin{tabular}{|c|c|c|c|c|c|c|c|c|}
\hline \multicolumn{9}{|c|}{$\frac{d C_{F e e d}}{d t}=\beta_{1}+\left(2 * \beta_{2}\right) t+\left(3 * \beta_{3}\right) t^{2}+\left(4 * \beta_{4}\right) t^{3}+\left(5 * \beta_{5}\right) t^{4}+\left(6 * \beta_{6}\right) t^{5}+\left(7 * \beta_{7}\right) t^{6}$} \\
\hline Experimental condition & Sample & $\beta_{1}$ & $\left(2 * \beta_{2}\right)$ & $\left(3 * \boldsymbol{\beta}_{3}\right)$ & $\left(\mathbf{4} * \boldsymbol{\beta}_{4}\right)$ & $\left(5 * \boldsymbol{\beta}_{5}\right)$ & $\left(6 * \beta_{6}\right)$ & $\left(\mathbf{7} * \boldsymbol{\beta}_{7}\right)$ \\
\hline \multirow{12}{*}{$\begin{array}{l}{[\mathrm{Cr}(\mathrm{VI})]} \\
\begin{array}{l}5.0 \times 10^{-4} \mathrm{~mol} \mathrm{~L}^{-1} \\
\text { pH 3.0 }\end{array}\end{array}$} & MPP & 0 & 0 & $-4.18 \times 10^{-13}$ & $9.34 \times 10^{-16}$ & 0 & 0 & 0 \\
\hline & MClV1 & 0 & $-2.77 \times 10^{-8}$ & $7.43 \times 10^{-10}$ & $-7.08 \times 10^{-12}$ & $2.99 \times 10^{-14}$ & $-5.81 \times 10^{-17}$ & $4.20 \times 10^{-20}$ \\
\hline & MClV2 & $-3.48 \times 10^{-7}$ & 0 & $1.36 \times 10^{-10}$ & $-1.74 \times 10^{-12}$ & $8.23 \times 10^{-15}$ & $-1.67 \times 10^{-17}$ & $1.23 \times 10^{-20}$ \\
\hline & MNG1 & $-2.76 \times 10^{-7}$ & 0 & $3.06 \times 10^{-12}$ & 0 & 0 & $-1.84 \times 10^{-20}$ & 0 \\
\hline & MNG2 & $-3.08 \times 10^{-7}$ & 0 & 0 & $1.00 \times 10^{-13}$ & $-4.45 \times 10^{-16}$ & $5.11 \times 10^{-19}$ & 0 \\
\hline & & \multicolumn{7}{|c|}{$\frac{d C_{\text {Receiving }}}{d t}=\beta_{1}+\left(2 * \beta_{2}\right) t+\left(3 * \beta_{3}\right) t^{2}+\left(4 * \beta_{4}\right) t^{3}+\left(5 * \beta_{5}\right) t^{4}+\left(6 * \beta_{6}\right) t^{5}+\left(7 * \beta_{7}\right) t^{6}$} \\
\hline & Sample & $\beta_{1}$ & $\left(2 * \beta_{2}\right)$ & $\left(3 * \boldsymbol{\beta}_{3}\right)$ & $\left(4 * \beta_{4}\right)$ & $\left(\mathbf{5} * \boldsymbol{\beta}_{5}\right)$ & $\left(6 * \beta_{6}\right)$ & $\left(\mathbf{7} * \boldsymbol{\beta}_{7}\right)$ \\
\hline & MPP & 0 & 0 & $3.70 \times 10^{-13}$ & $-8.26 \times 10^{-16}$ & 0 & 0 & 0 \\
\hline & MClV1 & 0 & $2.86 \times 10^{-8}$ & $-7.65 \times 10^{-10}$ & $7.28 \times 10^{-12}$ & $-3.09 \times 10^{-14}$ & $5.98 \times 10^{-17}$ & $-4.32 \times 10^{-20}$ \\
\hline & MClV2 & $3.59 \times 10^{-7}$ & 0 & $-1.40 \times 10^{-10}$ & $1.79 \times 10^{-12}$ & $-8.47 \times 10^{-15}$ & $1.72 \times 10^{-17}$ & $-1.27 \times 10^{-20}$ \\
\hline & MNG1 & $2.84 \times 10^{-7}$ & 0 & $-3.15 \times 10^{-12}$ & 0 & 0 & $1.89 \times 10^{-20}$ & 0 \\
\hline & MNG2 & $3.17 \times 10^{-7}$ & 0 & 0 & $-1.03 \times 10^{-13}$ & $4.59 \times 10^{-16}$ & $-5.26 \times 10^{-19}$ & 0 \\
\hline & & \multicolumn{7}{|c|}{$\frac{d C_{F e e d}}{d t}=\beta_{1}+\left(2 * \beta_{2}\right) t+\left(3 * \beta_{3}\right) t^{2}+\left(4 * \beta_{4}\right) t^{3}+\left(5 * \beta_{5}\right) t^{4}+\left(6 * \beta_{6}\right) t^{5}+\left(7 * \beta_{7}\right) t^{6}$} \\
\hline Experimental condition & Sample & $\beta_{1}$ & $\left(2 * \boldsymbol{\beta}_{2}\right)$ & $\left(3 * \boldsymbol{\beta}_{3}\right)$ & $\left(\mathbf{4} * \boldsymbol{\beta}_{4}\right)$ & $\left(\mathbf{5} * \boldsymbol{\beta}_{5}\right)$ & $\left(6 * \beta_{6}\right)$ & $\left(\mathbf{7} * \boldsymbol{\beta}_{7}\right)$ \\
\hline \multirow{10}{*}{$\begin{array}{c}{[\mathrm{Cr}(\mathrm{VI})]} \\
5.0 \times 10^{-4} \mathrm{~mol} \mathrm{~L}^{-1} \\
\text { pH 9.0 }\end{array}$} & MPP & $-1.77 \times 10^{-7}$ & $1.35 \times 10^{-9}$ & $-2.28 \times 10^{-12}$ & 0 & 0 & 0 & 0 \\
\hline & MClV1 & 0 & $-3.16 \times 10^{-8}$ & $1.33 \times 10^{-10}$ & 0 & $-3.18 \times 10^{-16}$ & 0 & 0 \\
\hline & MClV2 & $-5.97 \times 10^{-7}$ & 0 & 0 & $2.58 \times 10^{-14}$ & 0 & $-9.66 \times 10^{-20}$ & 0 \\
\hline & MNG2 & $-2.99 \times 10^{-7}$ & 0 & 0 & 0 & $9.24 \times 10^{-17}$ & $-2.02 \times 10^{-19}$ & 0 \\
\hline & & \multicolumn{7}{|c|}{$\frac{d C_{\text {Receiving }}}{d t}=\beta_{1}+\left(2 * \beta_{2}\right) t+\left(3 * \beta_{3}\right) t^{2}+\left(4 * \beta_{4}\right) t^{3}+\left(5 * \beta_{5}\right) t^{4}+\left(6 * \beta_{6}\right) t^{5}+\left(7 * \beta_{7}\right) t^{6}$} \\
\hline & Sample & $\beta_{1}$ & $\left(2 * \boldsymbol{\beta}_{2}\right)$ & $\left(3 * \boldsymbol{\beta}_{3}\right)$ & $\left(\mathbf{4} * \boldsymbol{\beta}_{4}\right)$ & $\left(5 * \boldsymbol{\beta}_{5}\right)$ & $\left(6 * \beta_{6}\right)$ & $\left(\mathbf{7} * \boldsymbol{\beta}_{7}\right)$ \\
\hline & MPP & $2.77 \times 10^{-6}$ & $-2.10 \times 10^{-8}$ & $3.56 \times 10^{-11}$ & 0 & 0 & 0 & 0 \\
\hline & MClV1 & 0 & $3.26 \times 10^{-8}$ & $-1.37 \times 10^{-10}$ & 0 & $3.27 \times 10^{-16}$ & 0 & 0 \\
\hline & MCIV2 & $6.15 \times 10^{-7}$ & 0 & 0 & $-2.66 \times 10^{-14}$ & 0 & $9.95 \times 10^{-20}$ & 0 \\
\hline & MNG2 & $3.09 \times 10^{-7}$ & 0 & 0 & 0 & $-9.52 \times 10^{-17}$ & $2.09 \times 10^{-19}$ & 0 \\
\hline
\end{tabular}

\section{CONCLUSIONS}

Macroporous commercial PP membrane supports can be activated for the synthesis of ion exchange IPNs by employing thermal radical polymerization. The proper selection of the functional groups of the monomers, crosslinking agent and precursor concentrations play an important role in synthesis when considering the charge and network densities. The modification of the PP membrane proposed in this research produced samples with good stability and with the potential for use in water treatment or chromium recovery processes.

Through the characterizations (volumetric flux, modification degree, water uptake capacity, SEM, and charge density), the modification inside of the membranes is demonstrated.

The experimental data for $\mathrm{Cr}(\mathrm{III})$ and $\mathrm{Cr}(\mathrm{VI})$ ions in the feed and extraction chambers using the Donnan dialysis fit well to the mathematical models because the correlation coefficients for the modified membranes are very close to 1 . The 4-order polynomial equation for the $\mathrm{Cr}$ (III) ions and the 7-order polynomial equation for the $\mathrm{Cr}(\mathrm{VI})$ ions are better suited to the data and can predict the concentration values for any time. The characterization results through the Donnan method indicate that it is possible to model the results using conventional mathematical treatments to represent the behavior and make predictions for the performance of the membranes, as an alternative to the Nernst-Planck equations, which are commonly used to characterize membrane systems.

\section{ACKNOWLEDGMENTS}

The authors thank FONDECYT (Grants No 1150510 and 1191336), MECESUP 2 UCH0601, Ion Solutions SpA, and CIPA, Chile.

\section{REFERENCES}

1. Z. Yuan, X. Cheng, L. Zhong, R. Wu, Y. Zheng, J. Environ. Sci. 77, 75 (2019).

2. S. Xia, Z. Song, P. Jeyakumar, S. Shaheen, J. Rinklebe, Y. Ok, N. Bolan, H. Wang, Crit. Rev. Env. Sci. Tec. 49, 1027 (2019).

3. World Health Organization (W.H.O.), Human health risk assessment toolkit: chemical hazards, Geneva, 2010.

4. M. Shahid, S. Shamshad, M. Rafiq,S. Khalid,I. Bibi,N. Niazi, C. Dumat,M. Rashid, Chemosphere 178, 513 (2017).

5. T. Sardohan, E. Kir, A. Gulec, Y. Cengeloglu, Sep. Purif. Technol. 74, 14 (2010).

6. P. Szczepański, Desalination 444, 6 (2018).

7. Y. Tapiero, B. L. Rivas, J. Sánchez, E. Avila, J. Chil. Chem. Soc. 63, 3902 (2018).

8. J. Sánchez, C. Espinosa,Y. Tapiero, J. Santiago-García, D. Oyarzún, G. Pizarro,J. Water Process Eng. 30, 100619 (2019).

9. M. Gaikwad,C. Balomajumder, J. Mol. Liq. 234, 194(2017)

10. T. Z. Sadyrbaeva, Chem. Eng. Process. 99, 183 (2016).

11. M. Chiha, F. Ahmedchekkat, A. Al-Bsoul, Desalin. Water Treat. 57, 5567 (2016).

12. J. Ocaña-González, R. Fernandez-Torres, M. Bello-López, M. RamosPayan, Anal. Chim. Acta. 905, 8(2016).

13. L. L. Li, X. Q. Feng, R. P. Han, S. Q. Zang, G. Yang, J. Hazard. Mater. 321, 622 (2017)

14. S. Golbaz, A. Jafari, M. Rafiee, R. Kalantary, Chem. Eng. J. 253, 251 (2014)

15. U. Habiba, T. Siddique, T. Joo, A. Salleh, B. Ang, A. Afifi, Carbohyd. Polym. 157, 1568 (2017).

16. C. Agarwal, A. Goswami, J. Membr. Sci. 507, 119 (2016). 
17. N. Barlık, B. Keskinler, M. Kocakerim, G. Akay, Desalin. Water Treat. 57, 26440 (2016)

18. C. Agarwal, R. Cattrall, S. Kolev, J. Membr. Sci. 514, 210(2016).

19. D. Wan, S. Xiao, X. Cui, Q. Zhang, Y. Song, Environ. Earth Sci.73, 4923 (2015).

20. A. Tor, Y. Cengeloglu, M. Ersov, G. Arslan, Desalination 170, 151 (2004).

21. L. Chikh, V. Delhorbe, O. Fichet, J. Membr. Sci. 368, 1 (2011).

22. J. Zhao, Q. Shi, S. Luan, L. Song, H. Yang, H. Shi, J. Jin, X. Li, J. Yin, J. Stagnaro, J. Membr. Sci. 369, 5 (2011).

23. C. Agarwal, A. Pandey, S. Das, M. Sharma, D. Pattyn, P. Ares, A. Goswami, J. Membr. Sci. 415, 608 (2012).

24. J. Sánchez, B L. Rivas, Desalination 279, 338 (2011).

25. L. Toledo, B.L. Rivas, B. Urbano, J. Sánchez, Sep. Pur. Technol. 103, 1 (2013).

26. I. Santander, B.L. Rivas, B. Urbano, L. Leiton, I. Ipek, M. Yüksel, N. Kabay, M. Bryjak, Polym. Bull. 71, 1813 (2014).

27. M. Hammami, D. Ennigrou,K. Naifer, M. Ferid, Environ. Prog. Sustain. 35, 1091(2016)
28. Y. Lin, Y. Hong, Q. Song, Z. Zhang, J. Gao, T. Tao, Colloid Polym. Sci. 295, 627 (2017).

29. Y. Tapiero, J. Sánchez, B.L. Rivas, Polym. Bull. 73, 989 (2016).

30. Y. Tapiero, J. Sánchez, B.L. Rivas, Chinese J. Chem. Eng. 25, 938 (2017).

31. A. Szymczyk, P. Fievet, J. Reggiani, J. Pagetti, Desalination 115, 129 (1998).

32. W. M. Deen Analysis of transport phenomena, topics in chemical engineering, Oxford University Press, New York, 1998

33. A. Saffar, P. Carreau, M. Kamal, A. Ajji, Polymer 55, 6069 (2014).

34. G. Hurwitz, G. Guillen, E. Hoek, J. Membr. Sci. 349, 349 (2010).

35. S. J. Seo, B. C. Kim, K. W. Sung, J. Shim, J. D. Jeon, K. H. Shin, S. H. Shin, S. H. Yun, J. Y. Lee, S. H. Moon, J. Membr. Sci. 428, 17 (2013).

36. H. Y. Yu, Z. K. Xu, Q. Yang, M. X. Hu, S. Y. Wang, J. Membr. Sci. 281, 658 (2006).

37. J. Kotaś, Z. Stasicka, Environ. Pollut. 107, 263 (2000). 